\title{
First-Principles Study of Adsorption of Hazardous Atoms on the Silica Surface
}

\author{
Ankhzaya Ganbaatar ${ }^{1}$, Namsrai Tsogbadrakh ${ }^{2}$, Ochirkhuyag Baynjargal ${ }^{1}$, \\ Tamiraa Ganbold ${ }^{1, *}$ \\ ${ }^{I}$ Department of Chemical and Biological Engineering, School of Applied Sciences and Engineering, National \\ University of Mongolia, Ulaanbaatar 14201, Mongolia \\ ${ }^{2}$ Department of Physics, School of Arts and Sciences, National University of Mongolia, Ulaanbaatar 14201, \\ Mongolia \\ *Corresponding author. Email: tamiraa@seas.num.edu.mn
}

\begin{abstract}
In this study, the adsorption of hazardous atoms including lead on the silica surface $\left(\mathrm{SiO}_{2}[001]\right)$ was investigated using the first-principles method within the framework of density functional theory (DFT). We performed the full structural optimization and found the most stable configuration. Four different sites were considered for the surface of silica, as well as four different sites for the surface of silica with an Al atom, and the adsorption energy along with the equilibrium geometry was determined. When the absorption energy was calculated at the four positions, the surface of silica and the surface of silica with Al had the same higher absorption at the first site $(-6.66 \mathrm{eV}$ and $-9.11 \mathrm{eV})$. The value of the absorption energy indicates that a strong chemical bond has been formed between the lead and the surface. The maximum values for the absorption energy of the lead atoms were $-6.93 \mathrm{eV}$ for the silica surface and $-9.11 \mathrm{eV}$ for the silica surface with the $\mathrm{Al}$ atom. Furthermore, the structure added by aluminum with the ratio of 1:5 to build a similar structure of a zeolite crystal. Which provided more absorption energy. The value of the absorption energy indicates that a strong chemical bond has been formed between the lead and the surface. The density of state (DOS) is shown that the bandgap was $2.78 \mathrm{eV}$ for the silica surface and $2.65 \mathrm{eV}$ for the silica surface with $\mathrm{Al}$ atoms. The addition of the lead atom reduced the width of the bandgap due to the creation of a trapping layer within the bandgap.
\end{abstract}

Keywords: Silica, Lead adsorption, DFT, PW, GGA

\section{INTRODUCTION}

As globalization is taking place, industry and technology are developing rapidly all around the world. Environmental contamination is causing harmful effects on humanity due to the development of industry, especially heavy metals contamination. Our environment contains lead. For example, air, water, and soil. The World Health Organization (WHO) has declared malicious chemical substances including mercury and lead, which are heavy metals $[1,2]$. It is harmful to the human body. Also, WHO stated there is no allowed tolerance level for lead in the human body. Therefore, the quantity of lead in the environment must be decreased and extracted. Several methods such as adsorption and electrolysis reduce $\mathrm{Pb}$ amount from the polluted environment $[3$,
4]. The adsorption method is considered suitable for environmental restoration [5, 6]. Using zeolite as an adsorbent is time-saving and cost-effective due to its relatively large surface area and porous structure. Due to the availability of zeolite reserves in the form of clinoptilolite in Mongolia, we conducted a study on this structure.

Physical and chemical adsorptions can take place on the zeolite crystal surface [7]. Regeneration of the zeolite has to be considered after the adsorption process [8-10]. Therefore, the adsorption mechanism research is conducted when using this kind of material. Zeolite has a $\mathrm{TO}_{4}$ structure and $\mathrm{T}$ could be replaced as $\mathrm{Si}, \mathrm{Al}, \mathrm{Ti}, \mathrm{Ge}, \mathrm{Sn}, \mathrm{P}$ elements. Each of these elements bonded to four oxygens and create a tetrahedral structure. However, the clinoptilolite 
zeolite is a relatively large structure with around 100200 atoms in a cell, so running calculation takes a great amount of time. Chemical bonding energies can be defined by solving the Shrodinger equation at the molecular level. In this work, the chemical adsorption energies of the $\mathrm{Pb}$ atom were estimated in the silica surface using density functional theory (DFT) [1113]. Then, $\mathrm{Si}$ atoms were substituted by $\mathrm{Al}$ atoms to create a similar structure with the clinoptilolite zeolite. However, this small structure takes less time than bulk zeolite. Moreover, the ratio of $\mathrm{Si} / \mathrm{Al}$ atoms plays important role in [10].

Here, we present the results of a study from the adsorption of hazardous atoms on the silica surface using the first-principles method within the framework density functional theory (DFT).

\section{EXPERIMENTAL}

\subsection{Computational Methods}

The absorption of lead on the silica surface was studied using the QUANTUM-ESPRESSO package program [14-16] within the framework of DFT [17, 18]. We determined the total energy, the width of the restricted zone, the state density, and the surface absorption energy. First, we selected two exchangecorrelation energies by LDA-PZ [19] and GGA-PBE [20], to select the approximate method of electronic exchange-correlation energy. To select a suitable pseudo-potential, Ultrasoft (USPP) and PAW were performed and a total of four calculations were performed on the silica crystal structure.

The charge density is calculated by the $3 \times 3 \times 4$ grid using the Monkhorst-Pack (MP) scheme [21]. The geometrically optimized structure was found until the force at all relaxed atoms became less than $0.0257 \mathrm{eV} / \AA$. The cut off energy of the lattice integration to determine the charge density was chosen to be $420 \mathrm{Ry}$. The lattice parameters are also set to $\mathrm{a}=4.179 \AA$ and $\mathrm{c}=2.666 \AA$.

Then, a silica surface was created by the $2 \times 2 \times 1$ supercell along the $\mathrm{x}, \mathrm{y}$, and $\mathrm{z}$ axes, and then cut a surface as [001]. The lattice parameters of the supercell were $a=b=8.359 \AA$, and the vacuum height was $40 \AA$ along the $\mathrm{z}$-axis. In this calculation, the exchange-correlation energy and pseudo-potential approximation methods PZ or local density approximation and ultrasoft pseudopotential (USPP) were used. Four different positions were considered as a lead atom an adsorption site.

The next part of the calculation was taken a place by substituting $\mathrm{Si}$ atoms to $\mathrm{Al}$ atoms with a ratio of
1:5 (Al:Si). The clinoptilolite zeolite has a structure $\mathrm{Al}_{6} \mathrm{Na}_{6} \mathrm{O}_{72} \mathrm{Si}_{30}$ [22]. This change in the surface was made to create a similar structure with the clinoptilolite zeolite crystals. The ratio of $\mathrm{Al}$ and $\mathrm{Si}$ atoms plays important role in the zeolite properties [23]. The same calculations were performed on the new structure of the same surface.

The binding energy absorbed $\mathrm{Pb}$ atom was calculated by the surface of the lead atom is calculated using the following Equation (1) [12]:

$\mathrm{E}_{\mathrm{b}}=\mathrm{E}_{\text {(surf+atom) }}-\mathrm{E}_{\text {surf }}-\mathrm{E}_{\text {atom }}$

where $\mathrm{E}_{\text {(surf+atom) }}$ is the total energy of the complex, $E_{\text {surf }}$ is the total energy of the silica surface and $\mathrm{E}_{\text {atom }}$ is the total energy of the free $\mathrm{Pb}$ atom. The stability of the structure in which the surface is absorbed can be the reason for the negative bond energy.

\section{RESULTS AND DISCUSSION}

We first fully optimized the bulk $\mathrm{SiO}_{2}$ structure (Figure 1). To select the approximation of the pseudo-potential and the exchange-correlation energy, the values of the cell parameters were compared with the experimental values.

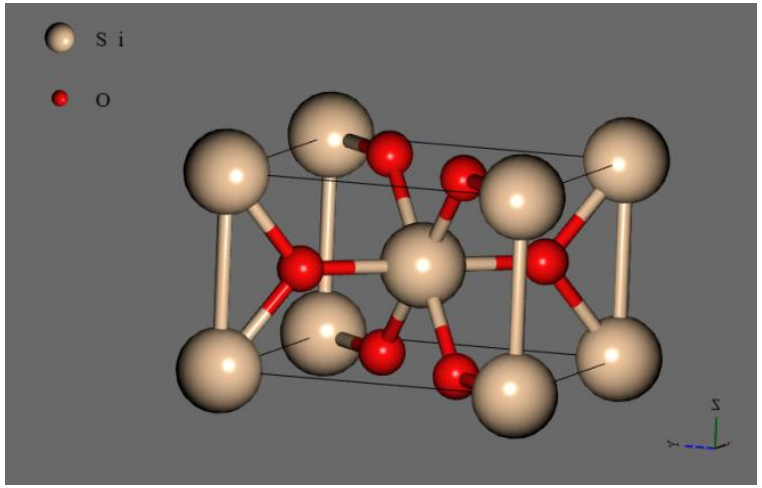

Figure 1. Crystal structure of $\mathrm{SiO}_{2}$

Four different potentials were considered for the calculation, and the results and experimental values were compared in Table 1. The suitable potential was chosen based on the lattice parameter values.

The four pseudo-potentials were considered in the baseline approximation and gave the closest value in PZ (exchange-correlation energy approximation) compared to the experimental value.

The pseudo-potential approximations of ultrasoft and PAW also gave the same value. However, PAW uses pseudo-potentials more extensively for magnetic 
properties studies, Ultrasoft has continued to use the pseudo-potential approximation method.

Table 1. Calculated cell parameters of $\mathrm{SiO}_{2}$ with four different pseudopotentials

\begin{tabular}{|l|l|l|l|l|l|}
\hline \multirow{2}{*}{$\operatorname{Exp}[\mathbf{2 4}]$} & \multicolumn{2}{l|}{ LDA - PZ } & \multicolumn{2}{l|}{ GGA -PBE } \\
\cline { 3 - 6 } & & USSP & PAW & USSP & PAW \\
\hline $\boldsymbol{a}(\mathbf{\AA})$ & 4.17 & 4.15 & 4.15 & 4.23 & 4.23 \\
\hline $\boldsymbol{b}(\mathbf{\AA})$ & 4.17 & 4.15 & 4.15 & 4.23 & 4.23 \\
\hline $\boldsymbol{c}(\mathbf{\AA})$ & 2.66 & 2.66 & 2.66 & 2.69 & 2.69 \\
\hline
\end{tabular}

Calculated the ground state of the silica surface, which was the resulting surface geometry with the lowest energy. The total DOS was calculated from the optimal structure to define the width of the bandgap, which was estimated by Equation (2) (Figure 2)

$E_{g}=2.78 \cdot \mathrm{eV}$
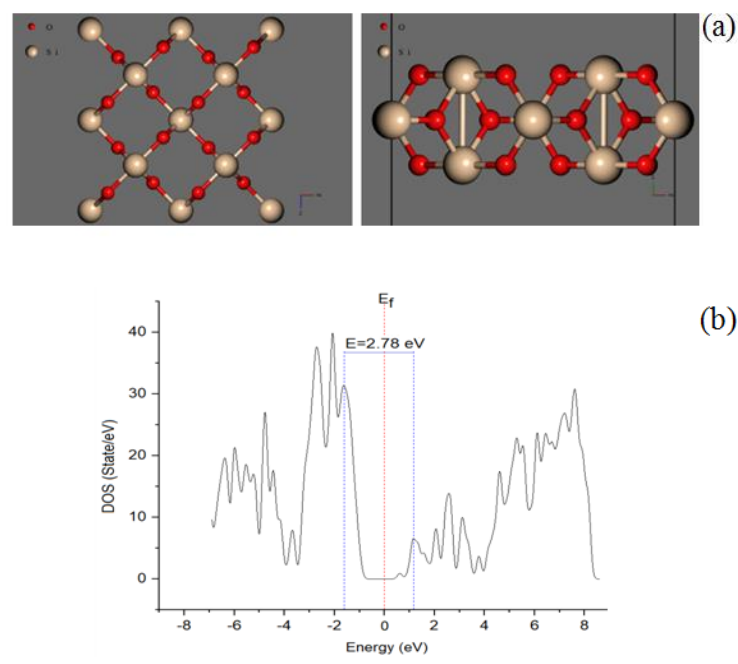

(b)

Figure 2. a) Top and side view of the optimized structure, b) Total DOS of $\mathrm{SiO}_{2}[001]$ surface.

The ground state of chemical bonding by placing lead atoms in four different positions on the resulting surface was studied by DFT (Figure 3).

In Figure 3, the left side is shown the initial position of the lead atom, and the right side is shown the final structure adsorbed the $\mathrm{Pb}$ atom in the surface.

At each of these positions, the minimum total energy of the ground state in the system was found using DFT to calculate the Schrödinger equation. Also, the total DOS corresponding to the state is calculated for the bandgap change. The ground state was determined by finding the minimum energy as a result of many iterations.
The first position was, the $\mathrm{Pb}$ atom is located offcentered and middle of two $\mathrm{Si}$ atoms and two $\mathrm{O}$ atoms. The lead atom is connected with one $\mathrm{Si}$ atom and one oxygen atom with the adsorption energy of $6.66 \mathrm{eV}$. The second position was chosen to be offcentered but middle of two $\mathrm{Si}$ atoms.
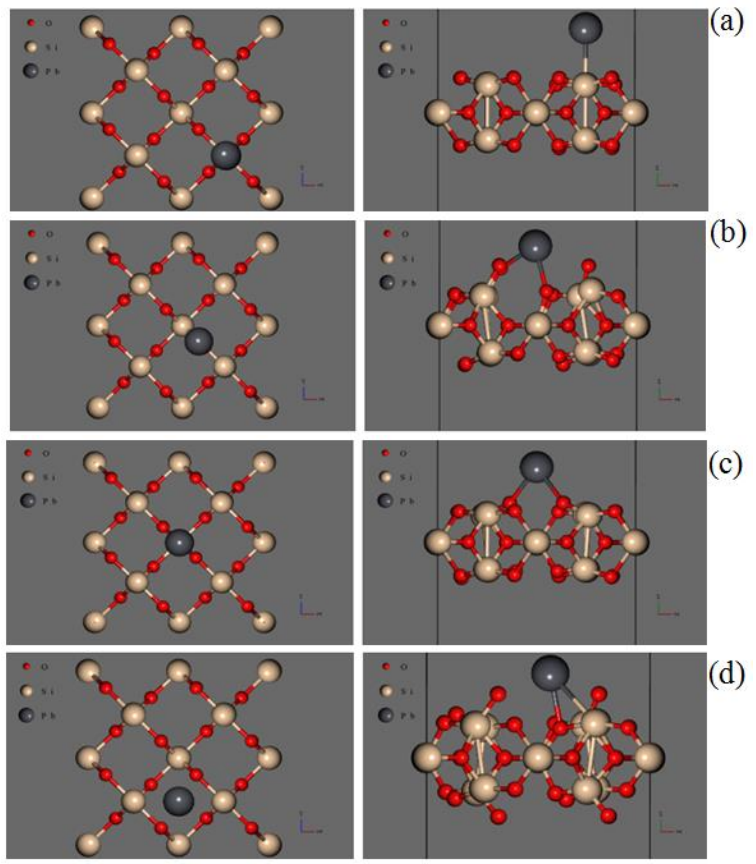

Figure 3. Initial configurations for adsorption of $\mathrm{Pb}$ atom and a) position $1, \mathrm{~b}$ ) position 2 , c) position $3, \mathrm{~d}$ ) position 4 on the $y$-x surface of $\mathrm{SiO}_{2}$ surface

After the optimization, the final structure showed the $\mathrm{Pb}$ atom created two oxygen bridge bonding. The adsorption energy was estimated as $-3.12 \mathrm{eV}$. Similar chemical bonding was created in the third position. In that position, the $\mathrm{Pb}$ atom was put in the center of the [001] surface. In this position, we found the lowest value of adsorption energy of $-6.93 \mathrm{eV}$, which can be the strongest chemical bonding among all. Finally, the $\mathrm{Pb}$ atom was located on top of one $\mathrm{Si}$ atom and connected with the $\mathrm{Si}$ atom. The energy value was $3.67 \mathrm{eV}$ in the last position. A negative sign indicates that a gravitational force is acting between the surface and the absorbing atom.

Among all of the four positions, the most stable strong bond was position 3 (See Figure 3c), with a bond energy of $-6.93 \mathrm{eV}$. The bandgap at this position became $E_{g}=1.65 \mathrm{eV}$. When lead atoms enter the surface in the form of doping, an additional exciting state is formed within the bandgap, which affects the width of the bandgap. The $\mathrm{Pb}$ atom acts like a defect or doping on the surface. Due to this effect, the width of the bandgap decreased. 
The absorption energies for each position are shown in Table 2.

Clinoptilolite zeolite has the structure $\mathrm{Al}_{6} \mathrm{Na}_{6} \mathrm{O}_{72} \mathrm{Si}_{30}$. The ratio of $\mathrm{Al}$ and $\mathrm{Si}$ atoms plays important role in zeolite properties.

Table 2. Adsorption energies of $\mathrm{Pb}$ atom onto the surface in each position

\begin{tabular}{|l|c|c|}
\hline & $\begin{array}{c}\text { Adsorption } \\
\text { energy (eV) }\end{array}$ & $\begin{array}{c}\text { Band gap } \\
(\mathbf{e V})\end{array}$ \\
\hline Position 1 & -6.66 & 1.26 \\
\hline Position 2 & -3.12 & 1.11 \\
\hline Position 3 & -6.93 & 1.65 \\
\hline Position 4 & -3.67 & 1.73 \\
\hline
\end{tabular}

Therefore, two Si atoms were substituted with 2 $\mathrm{Al}$ atoms, which keeps the 1:5 ratio in the silica $\left(\mathrm{Al}_{2} \mathrm{O}_{24} \mathrm{Si}_{10}\right)$ surface. The geometrically optimized structure surface was shown in Figure 4. In this case, considering the total DOS, the width of the bandgap was calculated to give $\mathrm{E}_{\mathrm{g}}=2.65 \mathrm{eV}$.
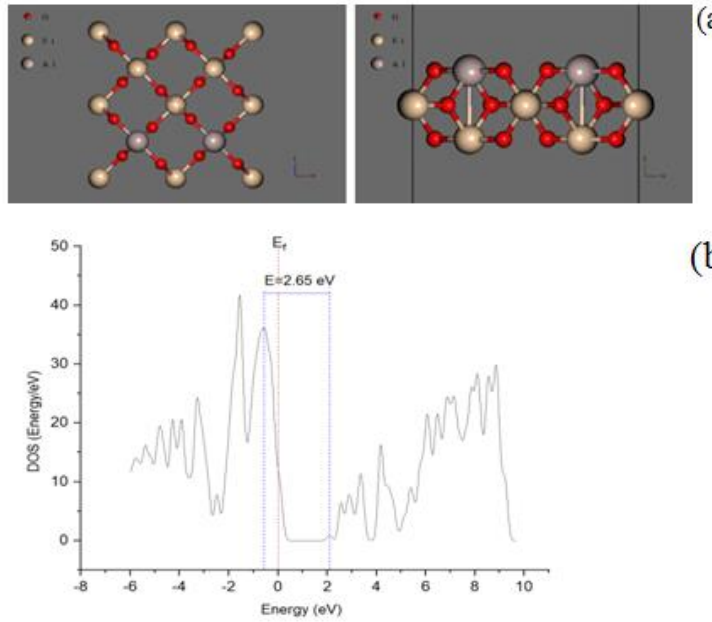

(b)

Figure 4. a) Optimized structure, b) Total DOS of $\mathrm{SiO}_{2}$ [001] surface with Al.

The surface also studied the absorption of lead atoms in four positions, as shown in Figure 5. In addition, DOS graphs were constructed at these positions and calculated the width of the bandgap.

The binding energy is calculated using the total energy of the system. The position shows that the $\mathrm{Pb}$ atom is conna-Siected with two oxygen atoms, which shows the bridge bonding with the adsorption energy of $-9.11 \mathrm{eV}$. In the second position, the $\mathrm{Pb}$ atom is connected with only the $\mathrm{Si}$ atom, and its bonding energy was estimated by $-2.17 \mathrm{eV}$. The two oxygen bridge bonding was created in the third position. The binding energy is $-8.97 \mathrm{eV}$. In the last position, the $\mathrm{Pb}$ was connected with 3 oxygen atoms. We considered that the result is feasible, due to the $\mathrm{Pb}^{+2}$ can connect with 2 atoms. The lowest adsorption energy was estimated by $-9.11 \mathrm{eV}$ in the first position. The bandgap became $2.18 \mathrm{eV}$ in that position.
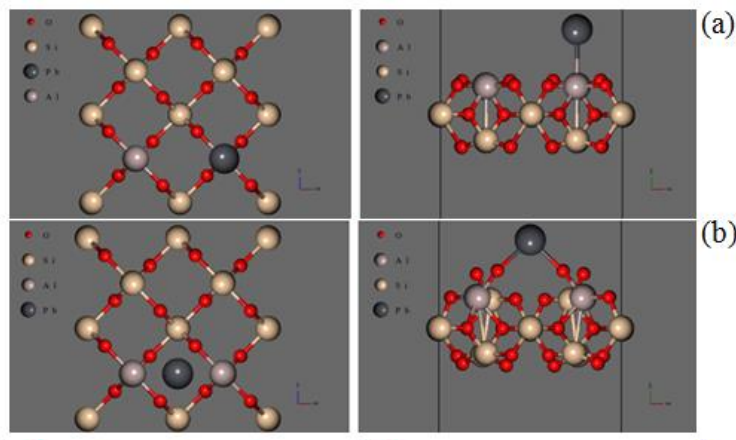

(a)
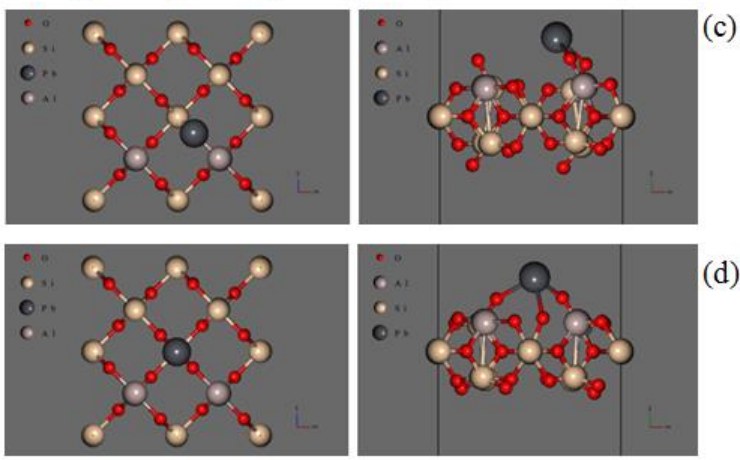

Figure 5. Initial configurations and $\mathrm{Pb}$ connected structures for adsorption of $\mathrm{Pb}$ atom a) position $1, \mathbf{b}$ ) position 2 , c) position 3 , d) position 4 on the $y-x$ surface of $\mathrm{SiO}_{2}$ surface with $\mathrm{Al}$ atom

The bond energies for each position are shown in Table 3.

Table 3. Adsorption energy of $\mathrm{Pb}$ atom onto the surface in each position

\begin{tabular}{|l|l|l|}
\hline & $\begin{array}{l}\text { Adsorption } \\
\text { energy }(\mathbf{e V})\end{array}$ & Band gap (eV) \\
\hline Position 1 & -9.11 & 2.18 \\
\hline Position 2 & -2.17 & 1.29 \\
\hline Position 3 & -8.97 & 1.32 \\
\hline Position 4 & -8.74 & 1.61 \\
\hline
\end{tabular}

\section{CONCLUSION}

Our study is shown that the lead atom made strong chemical bonding in the off-centered position on the $\mathrm{SiO}_{2}$ [001] surface. The chemical bond was formed by 2 oxygen bridges. For the Al case, we have shown that the chemical adsorption energy was estimated by $-9.11 \mathrm{eV}$ also in the off-centered position. The bonding is higher than the silica surface, which indicated that Al substituted structure can absorb the $\mathrm{Pb}$ atom more strongly. In both cases 
of strongest connections, the lead atom creates two oxygen bridges bonding. We indicated that the bandgap of the substituted structure is reduced, due to the $\mathrm{Al}$ atoms insertion in the lattice. Moreover, the $\mathrm{Pb}$ atom also acts as a doping effect in the lattice, which results in a reduction in the bandgap value.

\section{ACKNOWLEDGMENTS}

We would like to acknowledge Asian Research Center for supporting this study under project No. P2018-3621 and the Nano Center for its assistance in conducting this research.

\section{REFERENCES}

[1] Duruibe J.O., Ogwuegbu M.O.C., Egwurugwu J. N., (2007) Heavy metal pollution and human biotoxic effects. International Journal of Physical Sciences, Vol. 2, 112-118.

[2] Mohammed A.S., Kapri A., Goel R., (2011) Heavy metal pollution: source, impact, and remedies. In Biomanagement of metalcontaminated soils, Springer, Dordrecht, 1-28.

[3] Peng J.F., Song Y.H., Yuan P., Cui X.Y., Qiu G.L., (2009) The remediation of heavy metals contaminated sediment. Journal of Hazardous Materials, Vol. 161(2-3), 633-640.

[4] Li C., Zhong H., Wang S., Xue J., Zhang Z., (2015) A novel conversion process for waste residue: Synthesis of zeolite from electrolytic manganese residue and its application to the removal of heavy metals. Colloids and Surfaces A: Physicochemical and Engineering Aspects, Vol. 470, 258-267.

[5] Hong M., Yu L., Wang Y., Zhang J., Chen Z., Dong L., Li R., (2019) Heavy metal adsorption with zeolites: The role of hierarchical pore architecture. Chemical Engineering Journal, Vol. 359, 363-372.

[6] Shahmoradi A., Ahangari M.G., Jahanshahi M., Mashhadzadeh A.H., (2020) Adsorption of hazardous atoms on the surface of TON zeolite and bilayer silica: a DFT study. Journal of Molecular Modeling, Vol. 26(6), 1-13.

[7] McCabe W.L., Smith J.C., Harriott P., (1993) Unit operations of Chemical Engineering, New York: McGraw Hill.

[8] Ganzoury M.A., Chidiac C., Kurtz J., de Lannoy C.F., (2020) CNT-sorbents for heavy metals: electrochemical regeneration and closed-loop recycling. Journal of Hazardous Materials, Vol. 393, 122432.

[9] Lata S., Singh P.K., Samadder S.R., (2015) Regeneration of adsorbents and recovery of heavy metals: a review. International Journal of Environmental Science and Technology, Vol. 12(4), 1461-1478.

[10] Munkhbat D., Ganbold T., Naranbaatar A., Shiomori K., Bayanjargal O., (2020) Pb (II) adsorption of composite alginate beads containing mesoporous natural zeolite. Journal of Nanoscience and Nanotechnology, Vol. 20(8), 5267-5275.

[11] Mashhadzadeh A.H., Ahangari M.G., Salmankhani A., Fataliyan M., (2018) Density functional theory study of adsorption properties of non-carbon, carbon and functionalized graphene surfaces towards the zinc and lead atoms. Physica E: Low-dimensional Systems and Nanostructures, Vol. 104, 275-285.

[12] Mashhadzadeh A.H., Fathalian M., Ahangari M.G., Shahavi M.H., (2018) DFT study of Ni, $\mathrm{Cu}, \mathrm{Cd}$ and $\mathrm{Ag}$ heavy metal atom adsorption onto the surface of the zinc-oxide nanotube and zinc-oxide graphene-like structure. Materials Chemistry and Physics, Vol. 220, 366-373.

[13] Mashhadzadeh A.H., Vahedi A.M., Ardjmand M., Ahangari M.G., (2016). Investigation of heavy metal atoms adsorption onto graphene and graphdiyne surface: A density functional theory study. Superlattices and Microstructures, Vol. 100, 1094-1102.

[14] Gianmozzi P., Baroni S., Bonini N., Calandra M., Car R., et al., (2009) Quantum espresso: A modular and open-source software project for quantum simulations of materials. Journal of Physics: Condensed Matter, Vol. 21, 395502.

[15] Giannozzi P., Andreussi O., Brumme T., Bunau O., Nardelli M. B., et al., (2017). Advanced capabilities for materials modelling with Quantum ESPRESSO. Journal of Physics: Condensed Matter, 29(46), 465901.

[16] Giannozzi P., Baseggio O., Bonfà P., Brunato D., Car R., Carnimeo I., Baroni S., (2020) Quantum ESPRESSO toward the exascale. The Journal of Chemical Physics, Vol.152(15), 154105 . 
[17] Hohenberg P., Kohn W., (1964) Inhomogeneous electron gas. Physical Review Journals, Vol. 136, 864-871.

[18] Kohn W., ShamL J., (1965) Self-consistent equations including exchange and correlation effects. Physical Review Journals, Vol. 140, 1133-1138.

[19] Perdew J.P., Wang Y., (1992) Accurate and simple analytic representation of the electrongas correlation energy. Physical review B, Vol. 45(23), 13244.

[20] Perdew J.P., Burke K., Emzerhof M., (1996) Generalized gradient approximation made simple. Physical review letters, Vol. 77(18), 3865-3868.

[21] Monkhorst H.J., Pack J.D., (1976) Special points for Brillouin-zone integrations. Physical review B, Vol. 13(12), 5188.

[22] Munkhbat D., Shiomori K., Ochirkhuyag B., (2016) Characterization of Mongolian natural minerals and their application for heavy metal adsorbent. Mongolian Journal of Chemistry, Vol. 17(43), 50-54.

[23] Flanigen E.M., Jansen J.C., van Bekkum H. (Eds.)., (1991) Introduction to zeolite science and practice. Elsevier.

[24] Sugiyama M., Endo S., Koto K., (1987) The crystal structure of stishovite under pressure up to $6 \mathrm{GPa}$. Mineralogical Journal, Vol. 13(7), 455-466. 